\title{
Enabling Health Equity for persons with disability due to spinal cord injury
}

\author{
Marcalee Alexander ${ }^{1}$
}

Received: 20 October 2020 / Accepted: 26 October 2020

(C) International Spinal Cord Society 2020

2020 has been an unprecedented time for all of us. In addition to the vast human toll and loss of life caused by Covid-19, we must acknowledge other challenges. We have all had to rapidly change our lifestyles. Covid-19 has resulted in increased hardship upon an already difficult life for many. In contrast, for others that have had the means to take advantage, the pandemic has resulted in increased benefits and wealth. Still, on an individual level, there have likely been times when the glass has been both half empty and half full. If you are reading this you likely belong to one of two groups of individuals who have been hard hit this year: those of us working tirelessly to address the issues of people with spinal cord disorders and other disabilities, or those that live with spinal cord disorders and other disabilities. Perhaps, however, we can identify some positives. Spinal Cord Series and Cases is committed to educating people from all environments about SCI and our papers highlight the breadth of challenges people face. On the one hand we have shared the need for basic care such as clean water for hand hygiene in India [1], the second most populated country in the world, and the nascent use of intermittent catheterization in Tanzania [2]. Alternatively, we have discussed the impacts of such technologies as locomotor training [3], exoskeleton use [4], and spinal cord stimulation [5]. We have also shared knowledge about the direct impacts of COVID and the ability of this pathogen to result in associated SCD [6]. Regardless, as editor-in-chief, as demonstrated by the Africa and India collections, my passion has been to increase international knowledge of the challenges of people with SCIs in developing countries so that basic necessities are available to all persons with SCIs and SCDs.

Marcalee Alexander

spinalcordmd@live.com

1 Sustain Our Abiliities, Birmingham, AL 35242, USA
As a result of Covid-19, many rehabilitation centers have been temporarily closed or care patterns dramatically adjusted. Despite this, professionals have continued to tirelessly care for persons with SCIs, often at risk to their own health, for decreased salary, or with a loss of much needed vacation time. Concomitantly, persons with and without SCIs and SCDs, have been isolated and had to adapt to new problems, lost opportunities for face to face healthcare and for interaction with other individuals in similar circumstances. Rehabilitation, which was once a place of groups and camaraderie, has become a place for social distancing.

Another great change in the lives of professionals in Academia has been a halt in travel to continuing education meetings. While in our hearts we are all committed to our patients, it is also well-known that as leaders in Academia we have enjoyed the ability to fulfill our wanderlust and jetset across continents, despite the havoc that frequent travel can cause on one's family, coworkers, personal physical and emotional health, and offices. Fortunately, despite growing pains, we have successfully demonstrated that new forums for online education can allow greater variety of content and speakers to participate who may not be so lucky as to have a large travel stipend as part of their employment. Moreover, the cost of travel, both in terms of financial and environmental impact, can be tempered.

Excitingly, alternative methods of treatment have also recently expanded such as telerehabilitation, which can be beneficial in allowing more frequent follow-up between providers and individuals with SCI and their patients [7] or can help outreach to people without means to travel to a SCI center for care [8]. Furthermore, telerehabilitation can facilitate care in persons with SCI that are affected by disasters, a problem that will undoubtedly be more frequent in the future [9].

In moving forward and looking at the balance, we must be grateful we are in a time when technological advances have made these new forms of treatment and education possible. However, we must also balance the use of technology and advances in healthcare as we respond to a 
changing climate. Rather than using technology and access to healthcare as a means to increase the divide, we must learn to capitalize on our recent successes and ensure basic necessities are provided for persons with SCIs, regardless of where they are from or their socioeconomic status. For me, as a professional, a mother, a wife, a healthcare consumer and as a citizen of our only world, this is truly the way forward to a greener, healthier future for persons both with and without SCIs.

\section{Compliance with ethical standards}

Conflict of interest The author is the president of the nonprofit foundation, Sustain Our Abilities and receives no remuneration for this position.

Publisher's note Springer Nature remains neutral with regard to jurisdictional claims in published maps and institutional affiliations.

\section{References}

1. Swarnakar R, Santra S. Personal hygiene care in persons with spinal cord injury during the COVID-19 pandemic and lockdown: an Indian perspective. Spinal Cord Ser Cases. 2020;6:76. https:// doi.org/10.1038/s41394-020-00328-8.

2. Nade ES, Andriessen MVE, Rimoy F, Maendeleo M, Saria V, Moshi $\mathrm{H}$. et al. Intermittent catheterisation for individuals with disability related to spinal cord injury in Tanzania. Spinal Cord Ser Cases. 2020;6:66. https://doi.org/10.1038/s41394-020-0316-3.

3. Panza GS, Guccione AA. Effect of repeated locomotor training on ventilatory measures, perceived exertion and walking endurance in persons with motor incomplete spinal cord injury. Spinal Cord Ser Cases. 2020;6:94. https://doi.org/10.1038/s41394-020-00346-6.

4. Escalona MJ, Bourbonnais D, Goyette M, Duclos C, Gagnon DH. et al. Wearable exoskeleton control modes selected during overground walking affect muscle synergies in adults with a chronic incomplete spinal cord injury. Spinal Cord Ser Cases. 2020;6:26. https://doi.org/10.1038/s41394-020-0269-6.

5. Krucoff MO, Gramer R, Lott D, Kale E, Yadav AP, Muhammad M. et al. Spinal cord stimulation and rehabilitation in an individual with chronic complete L1 paraplegia due to a conus medullaris injury: motor and functional outcomes at 18 months. Spinal Cord Ser Cases. 2020;6:96. https://doi.org/10.1038/s41394-020-00345-7.

6. Sampogna G, Tessitore N, Bianconi T, Leo A, Zarbo M, Montanari E. et al. Spinal cord dysfunction after COVID-19 infection. Spinal Cord Ser Cases. 2020;6:92. https://doi.org/10.1038/s41394-02000341-x.

7. Irgens I, Bach B, Rekand T, Tormas S. et al. Optimal management of health care for persons with disability related to spinal cord injury: learning from the Sunnaas model of telerehabilitation. Spinal Cord Ser Cases. 2020;6:88. https://doi.org/10.1038/s41394020-00338-6.

8. Leochico CFD, Valera MJS. Follow-up consultations through telerehabilitation for wheelchair recipients with paraplegia in a developing country: a case report. Spinal Cord Ser Cases. 2020;6:58. https://doi.org/10.1038/s41394-020-0310-9.

9. Alexander M. Pandemics, climate change, and disability related to SCI. Spinal Cord Ser Cases. 2020;6:36. https://doi.org/10.1038/ s41394-020-0285-6. 